\title{
Number Marking in English and Thali: A Contrastive Study
}

\author{
Zafar Iqbal Bhatti ${ }^{1}$, Muhammad Asad Habib ${ }^{2} \&$ Tamsila Naeem ${ }^{1}$ \\ ${ }^{1}$ University of Management and Technology, Lahore, Pakistan \\ ${ }^{2}$ GIFT University Gujranwala, Pakistan \\ Correspondence: Zafar Iqbal Bhatti, University of Management and Technology, Lahore, Pakistan. E-mail: \\ ravianz902@gmail.com
}

Received: December 8, 2019 Accepted: January 10, 2020 Online Published: February 13, 2020

doi:10.5539/ijel.v10n2p255 URL: https://doi.org/10.5539/ijel.v10n2p255

\begin{abstract}
The aim of this paper is to explore the number system in Thali, a variety of Punjabi spoken by natives of Thal desert. There are three number categories singular, dual, and plural but all modern Indo Aryan languages have only singular and plural (Bashir \& Kazmi, 2012, p. 119). It is one of the indigenous languages of Pakistan from the Lahnda group as described by Grierson (1819) in his benchmark book Linguistic Survey of India. Layyah is one of the prominent areas of Thal regions. The native speakers of Thali use this sub dialect of Saraiki in their household and professional life. The linguistic boundaries of the present Siraiki belt have changed under different linguistic variational rules as described by Labov (1963), Trudgal (2004), Eckert (2002) and Meryhoff (2008). There are many differences between Thali and Saraiki, on phonological, morphological and orthographical levels. Husain (2017) has pointed out linguistic differences between Saraiki and Lahnda and Thali is one of the popular languages of Lahnda spoken in different parts of Thal regions. According to the local language activists, Thali has been greatly influenced by Saraiki and Punjabi. The lexicon of Thali is composed for $20 \%$ of Punjabi, $45 \%$ of Saraiki, and $5 \%$ of loan words particularly English. Another particularity is that Perso-Arabic characters are used to write Thali. The most distinguishing characteristics of Thali are its parts of speech, word order, case marking, verb conjugation and, finally, usage of grammatical categories in terms of number, person, tense, voice and gender. In this perspective, number marking is the area to focus on noun morphology and exclusively on the recognition of number system in Thali nouns. The analysis of linguistic systems including grammar, lexicon, and phonology provide sound justifications of number marking systems in languages of the world (Chohan \& García, 2019).
\end{abstract}

Keywords: Number, case, conjugation, voice and gender

\section{Introduction}

Borg and Alexander (1997) are of the view that majority of the worlds' languages carry three recognitions of number marking for the nouns of different languages in the world. They distinguish these by three decisive patterns like singular, dual, and plural like Thali.In this way, the singular form selected for conveying one entity, the dual form for expressing two objects, and lastly plural form which is expressed for three objects and more and more is stated like this. It means these three different morphological forms: singular, dual, and plural can express one, two, and three entities and more entities can also be expressed by using the same pattern.

In Welsh, number is marked on count nouns (singular and plural), demonstratives (that/those, this/these), gender and on one interrogative pronoun ( $p a$ un? -which (one) '? pa rai? -which (ones)'? The general method of making plural are internal vowel change and/or addition of suffixes.

According to Blake (1979), languages show different phenomenon as in western Queensland language, Kalkatungu, pronouns and demonstratives differentiate singular, plural and dual. Nouns are pluralized with a dual and plural marker. These are commonly used with kinship nouns as well as become part of the number system of demonstratives. As Masica (1991, pp. 225-226) pointed out the necessity of number for pronouns where rest of the plural suffixes are optional in Bengali.

According to the data, the three forms are not possessed by the same noun. In most of the cases only two forms are possible. On the other hand, the three semantic numbers are not connected with three forms: singular, dual, and plural. One entity is not always expressed by the singular form, two entities are nor expressed by the dual form and the three and more entities are always expressed by plural form. 


\section{MAP OF DISTRICT LAYYAH}

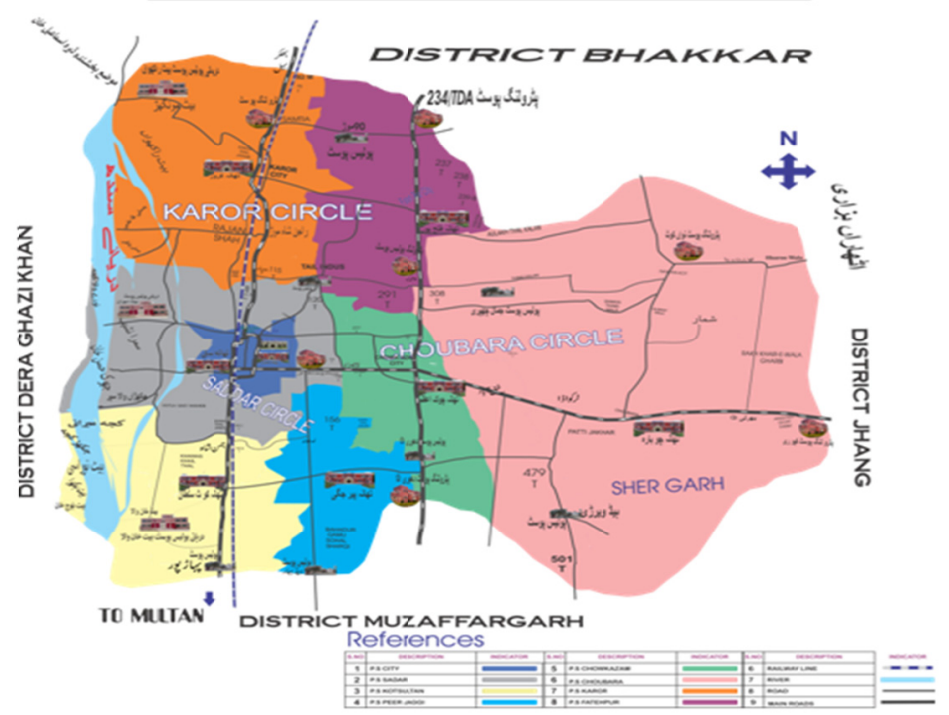

Figure 1. Comprehensive map of district Layyah of Punjab province, Pakistan

\subsection{Common Features}

Cardinal numbers can function both adjectives and nouns. The teen numerals are formed on the inherited [ $\mathrm{n}+10]$ pattern, that is the part of the number specifying the units place precedes the element meaning ten, e.g.,in /pandara/ 'fifteen 'the structure represents [5+10]. Numbers between twenty and one hundred are formed on the pattern [n+multiple of 10], as in /panti/. 'thirty-five

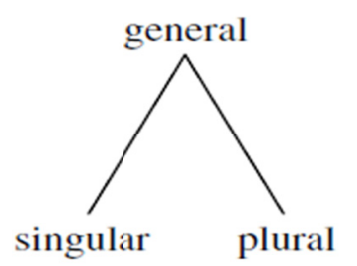

Figure 2. System with separate general number

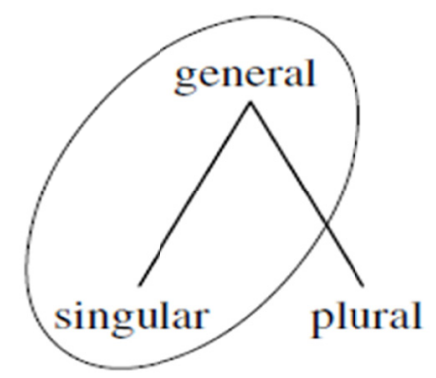

Figure 3. System with general singular versus plural

\subsection{Number-A Linguistic Category}

Number is a linguistic category which expresses some special information regarding individuality, plurality and numerosity in human speech. It touches the areas of morphology, semantics and morphosyntax in a language system. The absence of linguistic number is rare in languages spoken round the globe. There is clear opposition between 'one' and 'many' which is hidden in pronouns category where the speaker as 'one' is categorized by 
noun. It is also observed that nouns and determiners are categorized by number in different languages of the world. In different languages spoken around the world, there are formal devices to show number in lexical form (e.g., one, two, three, many, some) or grammatical form as plural marking system on verbs/or nouns. The number is nominal category which basically affects nouns and pronouns in different languages.

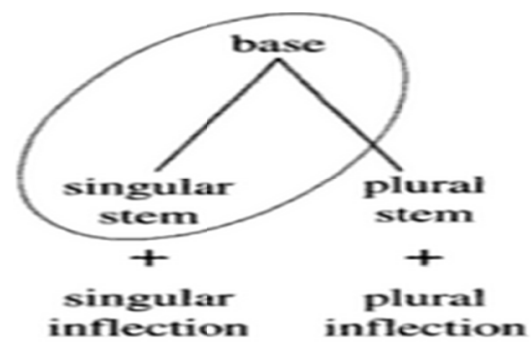

Figure 4. Singular stem matches the base

\subsection{Verbal Number}

It is a category of number which is related to different events which means shows the number of time and any state of happening (Veselinova, 2013). According to Corbett (2000), verbal number is restricted to small numbers of verbs but nominal number appears with observable variation in different languages of the world. The phenomenon of verbal number is found in many linguistic areas. The main possibility of verbal number is concerned with the number of participants as described by Durie (1986) as one eating is different from several eating together. It can be observed especially in North America (Mithun, 1988, p. 231). According to Steever (1987) in the South Central Dravidian group of languages of southern India and this verbal number event is also common in many African languages (Brooks, 1991) and Chadic group (Newman, 1990, pp. 53-87).

\subsection{Number Information Encoding}

There are ways to communicate number system in all languages of the world. According to Corbett (2000), there is big question regarding the process of encoding specific quantity information. They show how and where number information is being encoded whether it appears on grammatical categories like nouns, verbs, adjective etc. or is there any sort of agreement between linguistic categories which is marked for number is required as in the case of subject—verb agreement, or adjective-noun agreement. Thus, languages show variation in encoding some special aspects of number.

\subsection{Number Marking System - An Attachment of Lexical Item}

Number marking system shows an attachment of lexical item which shows a clear expression (e.g., three) or an estimated quantity (e.g., some).In a sentence, an argument can be modified by using this lexical item for example some students sing, three students sing or even it can stand in for the argument as some sing; three sing. On the other hand, number plans (devices) can show grammaticality and affixation to a noun, for example the word, "books" is the outcome of plural $-\mathrm{s}$ marker on the noun and the verb sings which shows agreement with the singular subject one student in the sentence, one student sings.

According to Diffloth (1992), there are several languages like English, show lexical and grammatical means of marking number and the rest of the languages keep only one system, these don't have any distinction of singular or plural nouns and grammatical number marking system as in the case of Khmer which has only number words for fulfilling the task. The number devices, lexical and grammatical appear in a communicative system and very central to language.

In this respect, there are many languages can be compared with English language. The number difference is very common in many languages round the globe. The verbal category is there instead of nominal category. In many cases, it is not obligatory but normally optional and irregular to the greater extent which becomes derivational category. In this context, Rapanui is the suitable example.

\subsection{Associative}

According to Moravcsik (1994), there are many languages having 'associative plurals' or 'group plurals'. The distinction between these and other plurals lies in the fact that these consists of a nominal plus with a marker. It further denotes an established set which is comprised of the main member 'the referent of the nominal'. This is 
also attached with more associated members. In making the pattern of these forms, 'Animacy Hierarchy' is kept under consideration for constructing the typology of these forms which are treated as a third number. These are considered exceptional by considering the ordinary plural or the associative plural. This is illustrated in the Figure 5 .

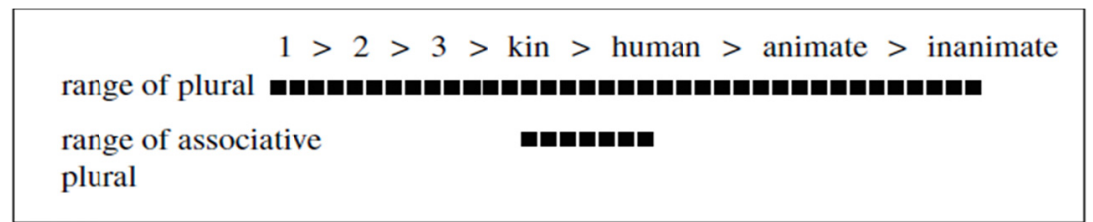

Figure 5. Associative plurals in Hungarian: analysis

\subsection{Dual-Grammatical Number}

The dual number is excessively used in different languages of the world. Dual is normally used as in addition to singular and plural by different languages including Proto-Indo-European. It is also used 'dual' as a grammatical number which is interpreted as refer to two objects or persons. This is used in this linguistic atmosphere when a noun or pronoun appears in dual form in the sentence. There are some other special verbs that can also have dual agreement forms in languages like Arabic, Hebrew and Maltese. According to Masica (1976), the dual number has also been found in languages such as Sanskrit and ancient Greek. The existence of dual number has been observed as dual forms across adjectives, verbs, nouns in these languages has been used as dual forms as verbs and pronouns. According to linguists, the traces of dual forms are still present in a few modern Indo-European languages. The researchers have enumerated these languages with the intensity of using dual form in these languages such as Scottish, Sorbian, Gaelic, Slovene and Lithuanian languages across the globe.

English is one of the modern Indo-European languages which also has lost dual but its residual traces are still present after developmental processes. In all above-mentioned languages, the special function of dual has been replaced by simple plural. As it has been observed as an evident of the examples: either vs. any, both vs. all, neither vs. none and many others. The very suitable example of plural is the following sentences:

(a) Both friends study in the same school

(b) Either he or his enemy has spread this rumor in the town.

(c) Neither you nor your friend defied the traffic authorities.

In the above examples words 'both', 'either', 'neither' refer to two persons who had been anticipated in the respective conversation.

\subsection{Number Words}

Some languages have specific features by which number system is expressed. For indicating number, 'number words' are used. In Tagalog, the word $m g a$ [maija] is used to pluralize any constituent.

First of all, the data are presented for demonstrating different configurations between the three forms: singular, dual, and plural for the present study. The next step is to analyze different hypotheses regarding these three forms to propose final verdict for getting facilitation to analyze and explain the realization of number marking system in Thali nouns with special reference to these three numbers: singular, dual, and plural.

\section{The Data}

\subsection{The Classification}

In Thali noun is one of the significant categories, can be distinguished in to three separate Classes.

It has been observed, two of the three inflected forms in all languages of the world are used by class $1 \& 2$ nouns. On the other hand, the three inflected forms are used by the Class 3 and 4 . The following examples clearly demonstrate this by presenting the data of Thali language and of English. The contrastive analysis presents the vivid picture of this classification.

\section{Class 1: nouns with two forms: singular-plural}

The following table shows the Class 1 carries two forms, only one entity is expressed by a singular form. While the more than one entity is expressed by a plural form. In this way, two entities or more than two entities are expressed by a plural form in the languages of the world. 
Table 1. Class 1

\begin{tabular}{llll}
\hline & One object & Two objects & Three objects and more \\
\hline CLASS 1 & kuker & kukrin & kukrin \\
& hen & hen-PL & hen-PL \\
\hline
\end{tabular}

The table shows the plural form is used for these nouns of English and Thali, where more than one entity is available in the table of comparison.

\section{Class 2: nouns with two forms: singular-dual}

In class 2 nouns, a plural number is expressed by two forms, firstly, a singular form and secondly, a dual form.

Table 2. Class 2

\begin{tabular}{llll}
\hline & One object & Two objects & Three objects and more \\
\hline CLASS 2 & yungh & yunghan & yunghan \\
& leg & legs-DU & legs- DU \\
\hline
\end{tabular}

The critics (grammarians) emphasize that things of different areas like body parts which are placed in different sets, resultantly these sets are structurally suffixed. Thali speakers as structures communicating absolutely two elements, yet as structures communicating more than one substance in the form of a plural number. Fenech (1996) used the term 'plural allomorph' for describing the nature of dual in the form of adding suffix. He further gave an example of a body part. The expression of dual in Thali can be explained like the following examples:
1) a. Thali
ghitah
b. ghitay
English ankle
ankle-

Dual

\section{Class 3: nouns of three forms: singular-dual-plural}

In class 3 nouns, there are three forms for expressing different number of entities. In this way, a singular, a dual and plural forms are used to express precisely a number of two, three and more than three entities in languages like English and Thali.

Table 3. Class 3

\begin{tabular}{|c|c|c|c|}
\hline & One object & Two objects & Three objects and more \\
\hline CLASS 3 & $\begin{array}{ll}\text { raat } & \\
& \text { night }\end{array}$ & $\begin{array}{l}\text { raatan } \\
\text { night -DU }\end{array}$ & $\begin{array}{l}\text { raatan } \\
\text { night -PL }\end{array}$ \\
\hline
\end{tabular}

\section{Class 4: nouns of three forms: singular-plural-dual}

Class 4 nouns have three forms for expressing different number of entities. In this way, a singular, a dual and plural forms are used to express precisely a number of two, three and more than three entities in languages like English and Thali.

Table 4. Class 4

\begin{tabular}{llll}
\hline & One object & Two objects & Three objects and more \\
\hline CLASS 4 & lohar & lohar & lohar \\
& blacksmith & blacksmith-DU & blacksmith-PL \\
\hline
\end{tabular}

The data show an aspect of semantics, e.g., nouns have three numbers, demonstrate number, time.

It is clear that three numbers are possessed by nouns which fulfil the parameters of semantics like time, number, etc. Thali also carries different words for showing semantics aspect of language. For example,the old Thali weights, old Thali measures (ratti, masa, tola, adhwar, etc) consumer numbers (quarter, chothai, tahai, pona, sawa, adhai, sadhay etc.) old Thali coins (thepa). Along all these, Thali keeps also basic food items, and some familiar objects from the social life where the number system works appropriately. 
According to Fenech (1996) use the term 'real dual' which expresses specifically two entities. This 'real dual' is connected with nouns of class 4 .

It has been observed that the dual forms of class 3 and 4 are similar. As well as the dual forms of Class 2 and Class 1 are similar in morphological structure. Accordingly, classes 3 and 4 nouns hold a paradigm having three forms. This paradigm shows a striking similarity to the classes 1 and 2 which contain not any form which is singular.

Table 5. Peroration of the forms

\begin{tabular}{llll}
\hline & Class 1 & Class 2 & Class 3 \\
\hline ONE ENTITY & Singular & Singular & Singular \\
TWO ENTITIES & Plural & Dual & Dual \\
THREE ENTITIES \& MORE & Plural & Dual & Plural \\
\hline
\end{tabular}

\subsection{The Realization of the Marks}

In this analysis part it clearly shows the series of analysis in which number marking system is explained with suitable examples and is presented with the marking mechanism which makes the structure of different forms of singular, the dual, and the plural in English and Thali. As it is shown that number marking is morphological marking where singular is unmarked, suffixation is used to mark dual and suffixation is also used for marking plural. Some other morphological processes are also used for marking plural nouns.

\section{Singular}

When noun is in the singular form it is unmarked (neutral). This notion provides basis to place nouns in the dual and plural categories. By keeping in view the collected data, the following singular forms are suitable examples:

\begin{tabular}{ll}
\hline Singular (unmarked) Thali & Glossing \\
\hline āh & curse \\
rāh & path \\
deed & look \\
\hline
\end{tabular}

\section{Dual}

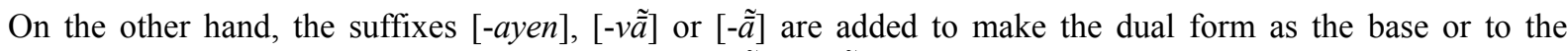
singular form in Thali. It has been also noted that $[-v \overline{\tilde{a}}]$ or $[-\tilde{a}]$ are actually the two forms of the same suffix. The linking vowels $[-a-]$ and $[-\tilde{a}]$ show the variation in the usage of the native speakers but these linking vowels are phonologically conditioned. The suffixes $[-v \tilde{\bar{a}}-]$ and $[-\tilde{\bar{a}}-]$, have been noticed the two variants which becomes the responses of the other two forms which are counterpart to the previous one, these forms are [-ayen] and $[-v \tilde{a}]$.These forms function as a supplementary suffix, and also named as the attached pronominal pronoun. The study recommends that the dual suffix as illustrated in the following examples in the full form of which precedes is not possible in Thali as in the form of pronominal pronoun.
2) a. $\tilde{\bar{u}}$ dā pær
foot-SG (M)
his feet
b. ũde pær
DUAL-POSS/GEN
his feet
3) a. $\tilde{\tilde{u}}$ de kitab
book-DUAL-POSS
b. $\tilde{\bar{u}}$ deã kitabã
leg-DUAL-POSS
his book
book-Dual-POSS

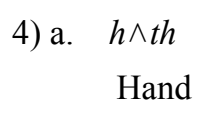
b. $h \wedge t h \overline{\bar{a}}$
hand-DUAL
hands

\section{Plural}

According to the data, the plural system of Thali nouns is very similar like Indo-European languages especially English. Thali like other Lahnda group of languages like Hindko, Punjabi, Jatki having postpositions. On the contrary, European languages having preposition system. There are different types of plural system in Thali like 
broken, suffixed and irregular plurals, normally used in daily routine.

The data show different types of suffixal elements for making plural in Thali nouns. There are following suffixes show the origin of Lahnda group:
5) a. moli
priest (religious figure)
b. $m u l l \tilde{\tilde{a}}$
'priest'-PL
priests
6) a. khooh
'a small populated area' (hamlet)
b. khooh (unmarked)
'town'-PL
towns

("Khoo" is unmarked-normally these belong to the cast names, is an area of very small population, less than 100 houses)
a. senh
'owner'
b. saheinh
'owner'-PL
owners
7) a. charhoia
'cook'
b. charhoy
'cook'-PL cooks

Suffixes from Punjabi:
8) a. likh $\rightarrow$ likhat
b. likhatã
'write' $\rightarrow$ 'writing'
c. zinda $\rightarrow$ zindagi
'alive' $\rightarrow$ 'life'
writings-PL
d. zindagi $\tilde{\bar{a}}$
'lives'-PL

Suffixes from English'

9) a. kompooter

\section{b. kompooter}

Computer

computer-PL

\section{Computers}

Ratcliffe, Robert R. (1998) points out the process of making 'broken plural' which are also called internal plural which is an irregular plural. This is involved in bringing an internal change in the noun or adjective. In this process, an internal change is brought inside the singular form by changing the pattern of consonants and vowels. These broken plurals are also found in Thali:
10) a. jaib/khesa
'pocket'
b. jaiban/khesay 'pocket'-PL
pockets

A dissimilar essential action involves in making suppletive plurals or irregular plurals from singular.
11) a. run/zaal
'wife'
b. run $\tilde{\tilde{a}} / z a l \tilde{a}$
'wife'-PL
wives

\subsection{Summary}

The data show that different methods are involved in making dual and the plural but there are different problems with the following configuration:

Class- $1 \rightarrow$ Singular-Plural-Plural
Class-2 $\rightarrow$ Singular-Dual-Dual

The first configuration of the class 1 in which entities abovelare expressed to use the plural forms. The second configuration of the class 2 in which entities above1 are two, three and more. 


\section{Analysis}

The following hypotheses provide the parameters to analyze how to make a vivid situation of the realization of different numbers which can be counted as three on Thali nouns system. The occurrence of these numbers have been minutely focused and analyzed why very few nouns keep a specific form for representing each and every number.

Finally, at the end, the following solution was proposed:

\subsection{Hypotheses for the Study}

There are following three hypotheses to analyze the process of number marking:

H 1: A hypothesis is planned by contrasting two sides one is labelled as "a three slot paradigm" and the other can be presented for putting three classes of different nouns.

Table 6. A three slot paradigm

\begin{tabular}{cccc}
\hline & Singular & Dual & Plural \\
\hline Noun Class1 & + & - & + \\
2 & + & + & - \\
3 & + & + & + \\
\hline
\end{tabular}

The table clearly illustrates that Class 1 nouns cannot demonstrate two entities. On the other hand, Class 2 nouns cannot express more than two entities in linguistic communication process. This is actually not the case in the present scenario:

\section{2) Panj botlā \\ det-five bottles \\ 13) $\tilde{\tilde{u}}$ de dah $h \wedge t h$ in \\ det- ten hands the ten hands}

In above-mentioned examples, the both nominal phrases in $13 \& 14$ for noun classes $1 \& 2$, express five and ten objects.

H 2: 'Thali keeps a number system of nouns which can be interpreted as a kind of dichotomy where the category of singular is exactly opposite to non-singular' as proposed by Corbett (2000). He says that only two slots are with the noun paradigm. In this case, another type of noun is the deviant category Class 3 and it has minor number.

On the contrary, Class 3 becomes an exception and majority of nouns are in this category of nouns. This does not interpret the notion of identity among classes $1,2 \& 3$ which can be labelled as non-singular while the others are dual and plural.

Table 7. 'kuker' and 'Yungh' is illustrated by Singular/non-singular

\begin{tabular}{lll}
\hline & Noun Class 1 & Noun Class 2 \\
\hline Singular & Kuker(hen) & Yungh (leg) \\
Non-singular & Kukeri (hens) & Yunghan (legs) \\
\hline
\end{tabular}

Table 8. 'Raat' night in Thali

\begin{tabular}{llll}
\hline & Singular & Dual & Plural \\
\hline Class 3 & raat & rattan & rattan \\
\hline
\end{tabular}

H 3: It is unusual phenomenon to have numerous paradigms for the membership of the members in the similar grammatical category which is carrying identical forms, as it is hypothesized that three forms, which are not are constantly dissimilar, possessed by each noun of each class.

It has been noticed that two forms can be similar in a paradigm. The examples have already been dealt, can be accusative or nominative. The reason behind it, is the form in a linguistic scenario and this form with the possessive determiner which makes this identical for cases. In Thali, the number of adjectives having the similar 
forms for masculine and the feminine. The following examples show the validity of this statement:

\begin{tabular}{|c|c|c|}
\hline tfangi $\rightarrow(\mathrm{SG})$ & bhahũ tangi $\rightarrow(\mathrm{SG})$ & bhahũ tfangẽ (PL) \\
\hline 'good' & 'better' & 'best' \\
\hline gundi $\rightarrow(\mathrm{SG})$ & bhahũ gundi $\rightarrow(\mathrm{SG})$ & bhahũ gundi $\tilde{\bar{a}}(\mathrm{PL})$ \\
\hline 'bad' & 'worse' & 'worst' \\
\hline
\end{tabular}

Besides this, there are disagreement of dual in the verb, adjective and the noun. On the other hand, there is agreement in plural. It clearly shows that noun only can distinguish dual from plural not any other element.
17) a. tfanga dehen asi tfangaydeh-an a sun
nice day FUT come nice days DUALFUT come
$3^{\mathrm{e} P . P L} \quad 3^{\mathrm{e} P . P L}$

nice day will come nice days will come

The examples show that particular meaning and specific morphological form is possessed by each form. The second point is dealt with the clarity that three above mentioned noun classes are homogenous without any defection.

\subsection{Proposition of Solution}

According to the proposal three forms are possessed by Class 1 but there is no difference between dual and plural form, these are similar. On the other hand, three forms are possessed by Class 2 but here also plural and dual forms are similar. The result has been obtained by employing rules of referral demarcated by Zwicky (1991).

Rule A and Rule B provide a descriptive summary of classes $1,2 \& 3$.

Rule A: the plural is referred for making Class 1 nouns as dual

Rule B: the dual is referred for making Class 1 nouns as plural

Table 9. Zwicky (1991)'s "Rules of referral”

\begin{tabular}{rlll}
\hline & SINGULAR & DUAL & PLURAL \\
\hline Class 1 & kuker & & kukerein \\
2 & yungh & yunghan & raatan \\
3 & raat & raatan \\
\hline
\end{tabular}

It has been observed that particular forms are selected to express particular meaning in day to day communication. The proposed analysis is not constructed on the similar forms because the rules of referral describes the way of copying the form for creating another form in the linguistic structure. Resultantly, a detailed description is obtained with planned paradigms. In this situation, the similarity of non-singular forms is captured.

Table 10. Solution

\begin{tabular}{rlll}
\hline & SINGULAR & DUAL & PLURAL \\
\hline Class 1 & kuker & kukerein & kukerein \\
2 & yungh & yunghan & yunghan \\
3 & raat & raatan & raatan \\
\hline
\end{tabular}

By keeping in view Stump's (2001) framework, a replica can be planned by focusing on guidelines below carrying 5 essential points. 


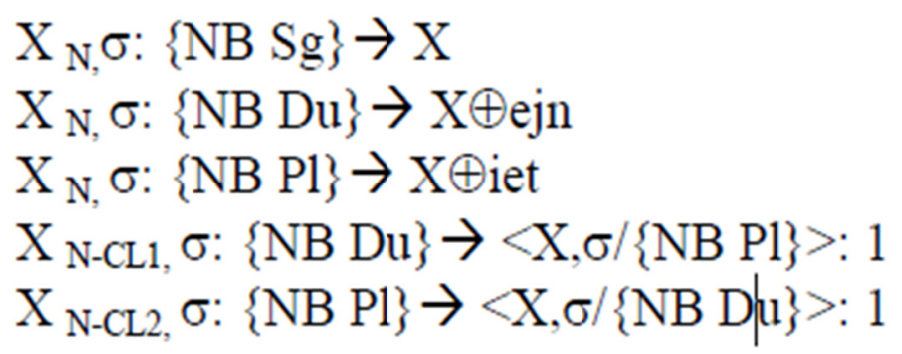

Figure 6. Adapted from Stump's (2001) framework

- The notion of noun singularity of the noun is taken the fundamental point which constructs a form labelled "unmarked" or "neutral form".

- The concept of duality a noun to the base in suffixes like [-ejn] is generated from the second rule.

- The way of making plural forms to the base in suffixes like [-in] is described by the third rule.

Furthermore, the remaining rules are called "rules of referral" proposed by Stump (1993) which respectively link to the following statements:

- In block 1, the realization of the plural number is referred by forming the dual of the nouns of Class 1

- In block 1, the realization of the dual number is referred by forming the dual of the nouns of Class 2

In the above mentioned rules, the distribution of the three numbers is explained by the analysis but in the case of irregular plurals, this analysis cannot be employed. In this situation, this can be adjusted by following "stem-space rule" proposed by Bonami and Boyé (2003). This rule describes that two stems are possessed by each noun. For example, the singular can be formed by Stem 1 and plural can be formed by Stem 2 .

Table 11. the rule of "Forms of the stem-space of the nouns

\begin{tabular}{lll}
\hline SINGULAR & DUAL & PLURAL \\
\hline Stem-1 & Stem-1 $\oplus$ ian & Stem-2 \\
\hline
\end{tabular}

The above-mentioned table shows the illustration of the rule of "Forms of the stem-space of the nouns" which has been applied in Thali.

\section{Conclusion}

In this paper, by using the rules of referral, a paradigm has been constructed for every noun. The current analysis is approved by Fenech (1996) and Corbett (2000). This gives a notion of constructing a homogenous paradigm possessed by a class. However, if class 1 would be unmarked or neutral and Class 3 would be marked accordingly, it would be become more convenient and plausible. The number systems in Thali share several features with other languages of Landha group like Punjabi, Shahpuri, Hindko.

\section{References}

Bashir, K., \& Abbas, K. (2012). Punjabi-English Dictionary Hyattsville. MD: Dunwoody Press.

Blanc, H. (1970). Dual and pseudo-dual in the Arabic dialects. Language, 46, 42-57. https://doi.org/10.2307/412406

Chohan, M. N., \& García, M. I. M. (2019). Phonemic Comparison of English and Punjabi. International Journal of English Linguistics, 9(4). https://doi.org/10.5539/ijel.v9n4p347

Corbett, G. G. (2000). Number. Cambridge, UK: Cambridge University Press.

Diffloth, G. (1992). Khmer. In W. Bright (Ed.), International encyclopedia of linguistics (pp. 271-275). Oxford, UK: Oxford University Press.

Durie, M. (1986). The Grammaticization of Number as a Verbal Category. In N. Vassiliki, V. Mary, M. Niepokuj \& D. Feder (Eds.), Proceedings of the twelfth Annual Meeting of the Berkeley Linguistics Society (pp. 355370). 15-17 February 1986, Berkeley, California: Berkeley Linguistics Society Publications. https://doi.org/10.3765/bls.v12i0.1876 
Dyła, S. (1984). Across-The-Board Dependencies and Case in Polish. Linguistic Inquiry, 15(4), 701-705.

Grierson, G. (1903-1921). Linguistic Survey of India (Reprinted ad Linguistic Survey of Pakistan, 5 Vols) Lahore: Sange Meel Publications.

Harbour, D. (2008). Morphosemantic Number: From Kiowa Noun Classes to UG Number Features. Studies in Natural Language and Linguistic Theory, Springer. https://doi.org/10.1007/978-1-4020-5038-1

Hockett, C. (1954). Two models of grammatical description. Word, 10, 210-234. https://doi.org/10.1080/00437956.1954.11659524

Hussain, A. K. (2007). Re-thinking Punjab: The Construction of Siraiki Identity. Research and Publication Centre (RPC) National College of Arts, Ferozsons (Pvt.) Ltd. Lahore Website: www.nca.edu.pkJrpc

Kibort, A., \& Corbett, G. G. (2008). Number. In Grammatical Features, University of Surrey.

Labov, W. (1963). The social motivation of a sound change. Word, 19(3), 273-309. https://doi.org/10.1080/00437956.1963.11659799

Masica, C. P. (1976). Defining a linguistic area: South Asia (pp. xiii, 234). Chicago: University of Chicago Press.

Meyerhoff, M., \& Nagy, N. (eds.). (2008). Social Lives in Language (p. 21). John Benjamins, ISBN 90-272-1863-3.

Mithun, M. (1988). The Grammaticization of coordination (pp. 331-359). John Benjamins Publishing Company. https://doi.org/10.1075/tsl.18.13mit

Montermini, F., \& Boyé, G. (2012). Stem relations and inflection class assignment in Italian. Word Structure, 5(1), 69-87. https://doi.org/10.3366/word.2012.0020

Moravcsik. (1994). Group plural: associative plural or cohort plural. Email document. Linguist, 5, 681.

Ratcliffe, R. R. (1998). The "Broken" Plural Problem in Arabic and Comparative Semitic (Current Issues in Linguistic Theory, p. 168). Amsterdam/Philadelphia: John Benjamins. ISBN 978-9027236739. https://doi.org/10.1075/cilt.168

Shackle, C. (1985). Language, Dialect and local identity in Northern Pakistan. In W. P. Zinge \& S. A. Lallament (Eds.), Pakistan in the 80s: Ideology, Regionalism, Economy, Foreign Policy (pp. 311-333). Lahore: Vanguard.

Steever, S. B. (1987). The origins of the past negatives in Konda. Journal of the American Oriental Society, 107(1), 71-88. https://doi.org/10.2307/602953

Veselinova, L. (2013). Negative existentials: a cross linguistic study. Italian Journal of Linguistics, 25, 17-146.

\section{Copyrights}

Copyright for this article is retained by the author, with first publication rights granted to the journal.

This is an open-access article distributed under the terms and conditions of the Creative Commons Attribution license (http://creativecommons.org/licenses/by/4.0/). 